\title{
USING TEAM-BASED LEARNING IN THE INTRODUCTORY INFORMATION SYSTEMS COURSE
}

\author{
Harry Benham, Montana State University, hbenham@montana.edu \\ Jerry Carvalho, Montana State University, jcarvalho@montana.edu
}

\begin{abstract}
This paper describes the impact on implementing Team-Based Learning $(T B L)$ in an undergraduate Introduction to Information Systems course. Team-Based Learning is briefly described. The purpose of using a TBL instructional format is to provide students with more opportunities to practice higher-order thinking skills on Information Systems content. Empirical results suggest that TBL does enhance student learning of Information Systems content.
\end{abstract}

Keywords: Team-Based Learning and Introductory Information Systems

\section{INTRODUCTION}

Information Systems instructors have struggled with the Introductory Information Systems course over the years. This course contains ideas and concepts vitally important to success of business in the $21^{\text {st }}$ Century. As with most introductory courses, there is a considerable number of acronyms and arcane terminology for the student to internalize. Frequently the Introductory Information Systems course also contains a hands-on computer application component. All too often, the Introductory Information System course winds up spending a great deal of class time on Remembering and Understanding, the two lowest levels of Bloom's revisited taxonomy [1] and relatively little time on Bloom's higher level cognitive work of Applying, Analyzing, Evaluating, and Creating. Thus students leave the Introductory Information Systems course having spent little time applying, analyzing, and evaluating the information systems ideas and concepts that will be so vital to their success and the success of the business.

Undergraduate business students will not all become information systems experts. Our goal is to provide students with the tools to recognize potential information systems issues in a business, the process knowledge to logically think through the issue, and the vocabulary to effectively communicate a recommendation for improvement to information system experts. We realized that our pedagogy would need to change to emphasize the critical thinking, problem solving, and communication goals.

Team-Based Learning (TBL) is a small group learning pedagogical approach pioneered by Michaelsen [6]. A Business Law colleague successfully redesigned her law class to emphasize recognizing legal issues in business, thinking through the problem logically, and then making good business decisions [3]. As there is a substantial literature supporting the use of small groups working together to enhance the learning of all group members and specifically a literature describing TBL in particular [7], we used TBL as the basis of our pedagogical changes in our Introductory Information Systems course.

This paper describes the results of implementing TBL in our Introductory Information Systems course. The next section provides a brief overview of the salient aspects of TBL. Next, we look at specifics of our Introductory Information Systems course and measures of TBL's impact on that course. The results of our analysis of TBL's impact are then presented. The final section provides discussion and conclusions.

\section{TEAM-BASED LEARNING}

TBL is well described in the literature [7] and will only be briefly summarized here. It is worthwhile to consider the key components of TBL, the teams, modules, readiness assessment tests, and in-class activities. Each component is discussed below. 


\section{TBL Teams}

TBL teams differ from other small group techniques in that they are persist through the course and they become teams rather than groups. Small group teaching techniques often ask students to form, on the fly, a small group to analyze a specific question or achieve some specific learning objective. In a group each member is responsible for only their own individual contributions. He or she achieves outcomes or makes their contribution. Within a group there is not the interconnectedness and shared responsibility that is seen between team members. Each member of a group can say "I did my best, it is not my fault that others did not pull their weight." With persistence, the group will develop a collective responsibility. In a team, individual members understand they are dependent on each other for achieving the final result. Consequently, team members have an interest in helping each other learn and master the course material.

\section{TBL Modules:}

A TBL course is typically divided into four to seven modules. Each module follows a distinct cycle. Individually, outside of class, students read assigned material and take a Readiness Assessment Test (RAT) on that material. Then the students retake the RAT in their teams. Following the RAT, teams complete a series of application exercises that where they apply, analyze, or evaluate based on their understanding of the material. Finally, a module wraps up with an individual student assessment of their understanding of the module's material.

\section{TBL Readiness Assessment:}

The Readiness Assessment Test (RAT) is a key to the success of TBL. In order to carve out class time for students to engage in higher level Bloom's taxonomy activities, lecture time cannot be spent on covering material students can master on their own. This is essentially the same as "Flipping the Classroom" [2, 4] although "Flipping the Classroom" is usually used in the context of electronic media to deliver content rather than reading a traditional textbook.

The individual RAT provides an incentive for the student to come to class prepared. The student is graded on his/her individual performance on the RAT. After the individual RAT, the team "re-takes" the same test. While the team RATs is being taken, it is not unusual to hear students hotly debate what the team's answer will be. And being able to contribute to the team's success is yet another incentive for students to be prepared.

After the team RAT has been completed, students receive immediate feedback on their performance. The final step in the RAT process is allowing teams to challenge the RAT answers. During the challenge phase, students are allowed to consult their textbook. If a team finds an answer they wish to challenge, they submit a written appeal. Written appeals are processed before the next class period. A successful appeal applies only to the team making the appeal.

The RAT process contributes to TBL's success in two ways. First, it motivates students to come to class prepared to improved their individual performance on the RAT and more importantly, to contribute to their teams performance on the RAT. Secondly, the RATs get students to discuss course content with each other. This happens first as the team does the RAT and again as the team consults the textbook or other content sources for an appeal.

\section{TBL In-Class Activities}

In-Class activities enable higher level learning. The RATs provide the foundational understanding, but it's the inclass activities that provide the application, analysis, and evaluation. Michaelsen and Knight [7] provide a detailed explanation of how to create effective in-class team assignments. The instructor needs to put considerable thought and creativity into the in-class assignments in order to fully engage students in higher level learning. Three guidelines are worth reporting here. First, teams should work on the same problem to allow comparison between group members and then between groups. These comparisons provide students with important feedback on both their thinking and their team's thinking. Second, a good in-class exercise will require students make a specific choice. Students need to engage in higher level thinking to identify more than one option, evaluate their options, and clearly articulate the case for their choice. Third, teams need to simultaneously report their choice. Teams can then challenge each other's decisions. Knowing they may be challenged causes teams to exercise greater care in crafting their justification for their choice. And challenging others may reveal weaknesses in their own though processes. 
The in-class activities vary by module. We often employ short case analysis using case problems from the textbook. We also use longer case based problems of our own creation on subjects such as Bring Your Own Device. Students write research papers on emerging technologies such as Cloud Computing or Wearable Technology. We have the students create and analyze small Decision Support applications in Excel and Access. We also include "fun" activities like encrypting and decrypting messages both within the team and across the teams.

In all cases we ensure that each team has access to at least one laptop computer. Teams are encouraged to go beyond the textbook as they hash out potential solutions to the problems presented.

Ultimately, TBL is about individual student learning. Beginning with the individual RAT, the individual is accountable for mastery of the basic content. Through the Team RAT and primarily through in-class team activities, the student is challenged to enhance their learning through applying concepts, analyzing situations, and evaluating alternatives. Each TBL module ends with an individual assessment.

\section{IMPLEMENTATION OF TBL}

Our Introduction to Information Systems course is fairly typical and compatible with most of the introductory textbooks on the market. The course does have a hands-on computer application component.

\section{Team Assignment}

It would be ideal to form teams on the first day of class. Unfortunately, class enrollment does not stabilize until late in the second week of instruction. Therefore teams were not formed until well into the second week. Teams are assigned by having all business students form one line and all non-business and international students form a second line. Students then count off in each line and all the "ones" become a group, the "twos" a second group, etc. The reason for having two lines is to try to increase the diversity within each team. The target team size is five or six individuals. Teams smaller than five are at risk of becoming too small should one or more of the members drop the course. Teams of more than six seem too large to function effectively.

Immediately after the teams are formed, they are asked to sit together and are given a few minutes to begin to get acquainted. Then we employ a practice RAT, using non-business content. Essentially, the students take their best shot at answering some multiple choice questions. Then they re-take the test as a group. Each team reports their individual minimum, average, and maximum scores plus the team score. Consistently, the team score exceeds the team average and frequently exceeds the individual maximum. The exercise is used to demonstrate that teams usually out-perform individuals and to emphasize the need to both speak-up and to listen in teams pointing to those instances where someone on a team actually did better than the team.

Some teams have free-riders. We offer our teams the option of "divorce" in the event that an individual team member persistently under-performs. We require two written notifications to an under-performing team member before a divorce. These written notifications must also contain the team's explicit performance expectations.

\section{Modules}

Most introductory information systems texts contain units, modules, or some other grouping larger than a chapter that can form the basis for creating TBL modules. Some care should be exercised to insure that the amount of content in each module is approximately the same. Also, each module will need in-class activities that require applying, analyzing, and evaluating.

\section{RATs}

Creating good RATs is difficult. Standard test-bank recall questions may be adequate for a quarter to a third of the RAT questions. Recall that part of the benefit of a RAT comes from team discussion of the answer. The questions requiring higher order thinking should be two thirds to three quarters of the RAT. Unfortunately, questions of this type occur less frequently in test-banks will take time and effort for the instructor to develop. 
One error we made initially was to not have sufficient numbers of higher-order thinking questions on the RAT. If the RATs are not sufficiently challenging, students may react by not preparing as well as they should and team discussions will be minimal.

\section{In-Class Exercises}

The in-class exercises are key to having students engage in higher-order thinking. Thankfully, many current textbooks contain mini-cases and application exercises that can be adapted to force students to make a specific choice. It frequently works well to have students produce a one page written individual response to the in-class exercises as homework. This insures that they have spent some individual time thinking about the situation and will have something to contribute to the team discussion. With very short write-ups, the instructor can quickly check that a student was prepared and focus evaluation on the group product.

\section{TBL's Impact}

We now have sufficient experience with a TBL approach to the Introductory Information Systems course that we can begin to look at its impact. We collected data on eight sections with four sections from before the TBL implementation and four sections after the TBL implementation. We have two different faculty each with at least one section prior to TBL and at least one section after TBL.

\section{Hypothesis Generation}

The purpose of switching to a TBL approach to the Introductory Information Systems course was to increase the amount of higher-order learning in the course. The null hypothesis to test is that TBL had no impact on student learning of Information System content.

\section{H1: There is no difference in student learning of Information Systems content between a TBL based Introductory Information Systems course and a traditional lecture format Introductory Information Systems course.}

As indicated above, our Introductory Information Systems course has a computer application component. We have a similar hypothesis for the computer applications component of the course. The hope is that the TBL based instruction of the information systems content does not detract from student performance on the computer application component of the course. It is a weak test, but we hope to not be able to reject our null hypothesis.

\section{H2: There is no difference in student performance on the computer applications as a result of TBL instruction in an Introductory Information Systems course.}

Data on student performance from eight sections will be used to test the above hypotheses.

\section{Measurements}

As with any course, changes occur over time in the assignments, assignment weights, and computer application assignments. Also, different instructors have somewhat different approaches and points possible. Scored or graded activities in these courses were examined and classified as pertaining to Information Systems content or computer application content. In each course the total points possible within each category was determined as well as the students point totals in each category. Student performance was measured by their percentage of the total points acquired in each category.

Students' percentages of total points on Information Systems assignments and exams and students' percentages of total points on computer application assignments and exams is an imperfect measure of the level of learning achieved. In support of this percentage of information systems points serving as a proxy for student learning is the fact that the Information System content assessments have not changed appreciably during the period studied. The assessments have consistently asked students applying, analyzing, and evaluating questions. 
As explanatory variables or controls, we have a number of dichotomous variables. The first is TBL Format indicated with a 1 if the course was taught using the TBL format. The Instructor variable distinguishes between Instructor A and Instructor B. An instructor's first time through a TBL format course may be problematic as the instructor gains experience with constructing RATs and In-Class activities. Instructor A was the first to try the TBL format in an Introductory Information Systems course. Instructor B moved to a TBL format after Instructor A and had the opportunity at least to learn from Instructor A's mistakes. The two variables, "First TBA A" and "First TBA B" indicate those sections taught for the first time by instructors A and B respectively.

\section{RESULTS}

Table I displays the results of a linear regression run used to test hypothesis $\mathrm{H} 1$. We can reject the null hypothesis that the TBL instruction format has no impact on student learning as measured by the percentage of points earned on Information Systems content. Ignoring for a moment the other controls, Table I indicates that students would "learn" approximately $71 \%$ of the Information Systems content under the traditional lecture-based format. The coefficient on TBL Format indicates that students taught in a TBL based Introductory Information Systems course "learned" $14 \%$ more. This is fairly strong support for TBL based instruction.

TABLE I

\begin{tabular}{|l|c|c|}
\hline \multicolumn{3}{|c|}{ Information Systems Content } \\
\hline \multicolumn{1}{|c|}{ Variable } & Coefficient & t-Stat \\
\hline Intercept & 0.7109 & 47.540 \\
\hline TBL Format & 0.1431 & $10.052^{* *}$ \\
\hline Instructor & -0.0091 & -0.671 \\
\hline First TBL A & -0.0326 & $-1.767+$ \\
\hline First TBL B & 0.0019 & 0.095 \\
\hline Adj. $\mathrm{R}^{2}$-Square & .218 & \\
\hline $\mathrm{N}$ & 602 & \\
\hline
\end{tabular}

+ significant at $10 \%$ level, $* *$ Significant at $1 \%$

level

Table I also indicates that there was no statistically significant impact of Instructor A's nor of Instructor B's first TBL based Introductory Information Systems course. However, the results do indicate that Instructor A's first TBL section was not as effective. Students in Instructor A's first TBL course offering "learned" about 3\% less than other students, all other things being equal.

TABLE II

\begin{tabular}{|l|c|c|}
\hline \multicolumn{3}{|c|}{ Computer Application Content } \\
\hline Variable & Coefficient & t-Stat \\
\hline Intercept & 0.8509 & 49.646 \\
\hline TBL Format & 0.0094 & 0.575 \\
\hline Instructor & -0.0150 & -0.968 \\
\hline First TBL A & -0.0704 & $-3.331^{* *}$ \\
\hline First TBL B & 0.0079 & 0.347 \\
\hline Adj. $\mathrm{R}^{2}$-Square & .218 & \\
\hline $\mathrm{N}$ & 602 & \\
\hline & $* *$ Significant at 1\% level \\
\hline
\end{tabular}

Table II reports the results testing hypothesis H2. Recall that the desired result was the TBL instruction should have no impact on students' computer application performance. The results in Table II clearly indicate that we are unable to reject the null hypothesis that the TBL instruction format has no impact on student performance on their computer application content. Failure to reject this null hypothesis is not strong evidence of no impact. But it is suggestive that there is virtually no evidence that the TBL instructional format does have an impact. 
Unfortunately Instructor A's difficulties in his first TBL course do appear to have had a negative on student's performance on their computer applications content. The coefficient on First TBL A in Table II indicates that students' performance was down about $7 \%$ for that first offering. Table II does not indicate any statistically significant differences due to Instructor nor did Instructor B's students exhibit in first TBL offering effects.

\section{CONCLUSIONS}

The results presented in Table I allow us to reject H1 and conclude that TBL instruction is associated with students earning about $14 \%$ more of the Information System available points. Table II suggests that the improvement in student performance on Information System content was not at the cost of lower performance on computer application content performance. Thus the data analysis is certainly supportive of using a TBL instruction format for Information System content.

A key component in the interpretation of the results reported in Tables I and II is the meaning of the dependent variables, the percentage of available points earned on Information Systems graded activities and computer applications graded activities. We have argued that students earning higher percentages of available points is indicative of students increased proficiency in dealing with Information Systems issues requiring higher order thinking involving applying, analyzing, and evaluating. We base this argument on the number and nature of exam questions remaining relatively constant during the period of this study.

Ideally, we should measure student learning directly, particularly their ability to apply, analyze, and evaluate in the Information Systems content domain. Perhaps as our assessment capabilities continue to improve, we will be able to make those measurements. In the interim, Table I provides empirical results strongly suggesting that a TBL instructional format improves student learning of Information Systems content in an Introductory Information Systems course.

\section{REFERENCES}

1. Andeson L.W. and D Krathwohl (2001). A Taxonomy for Learning, Teaching, and Assessing: A revision of Bloom's Taxonomy of Educational Objectives. New York: Longman.

2. Brame, C.J. (2013). Flipping the Classroom. Vanderbilt University, Center, http://cft.vanderbilt.edu/teaching-guides/teaching-activities/flipping-the-classroom/

3. Dana, S.W. (2007). Implementing Team-Based Learning in an Introduction to Law Course. Journal of Legal Studies Education, 24: 59-108.

4. DesLauriers L, E. Schelew, and C. Wieman (2011). Improved Learning in a Large-Enrollment Physics Class. Science. 332: 862-864.

5. Johnson, D.W. and R.T. Johnson. (1991) Cooperative Learning: Increasing College Faculty Instructional Productivity. New York: Wiley.

6. Michaelsen, L. K. (1992). Team learning: A comprehensive approach for harnessing the power of small groups in higher education. In To improve the Academy: Resources for faculty development, ed. D. H. Wulff and J. D. Nyquist, 107-22. Stillwater, OK: New Forums Press.

7. Michaelsen, L.K., A.B. Knight, and L.D. Fink. (2002). Team-Based Learning: A Transformative Use of Small Groups in College Teaching. New York: Greenwood Publishing Group.

8. Michaelsen, L.K. and A.B. Knight (2002). "Creating Effective Assignments: A Key Component of TeamBased Learning" in Michaelsen, et. al. (2002). Team-Based Learning: A Transformative Use of Small Groups in College Teaching. New York: Greenwood Publishing Group. 